\title{
Valores Organizacionais, Valores do Trabalho e Atitudes Retaliatórias: um Estudo com Jovens Aprendizes em uma Empresa Pública
}

\author{
Kely C M Paiva \\ Universidade Federal de Minas Gerais - Brasil \\ kelypaiva@face.ufmg.br \\ Ricardo Ken Fujihara \\ Universidade de Brasília -Brasil \\ ricardowho@gmail.com \\ Jennifer Fernandes Reis \\ Universidade Federal de Minas Gerais - Brasil \\ jenniferfernandesdosreis@hotmail.com
}

\section{Resumo}

Visando analisar como se configuram valores organizacionais, valores do trabalho e atitudes retaliatórias de jovens trabalhadores, realizou-se um estudo de caso em empresa pública. Dados de 508 questionários coletados em todo país foram analisados, pautando-se em estatística descritiva uni e bivariada. Quanto aos resultados da pesquisa, os valores "realização no trabalho" e "realização na organização" são os mais comungados pelos jovens aprendizes abordados, denotando certa congruência entre objetivos pessoais e organizacionais. Já o orgulho da organização não se reflete na mesma proporção em relação ao trabalho que efetivamente realizam, em face das diferenças encontradas entre "prestígio organizacional" e "prestígio no trabalho". A posição dos jovens com relação às atitudes retaliatórias foi previsível, tendo em vista sua aderência aos valores compartilhados, em ambos os níveis observados, e sua pouca experiência de trabalho e na vida, de modo geral. Os resultados dos testes de correlação surpreenderam devido a sua heterogeneidade quando do cruzamento dos temas.

Palavras-chave: valores organizacionais, valores do trabalho, atitudes retaliatórias, jovens 
Teoria e Prática em Administração, v. 7, n. 1, jan/jun 2017 - ISSN: 2238-104X Valores Organizacionais, Valores do Trabalho e Atitudes Retaliatórias: um Estudo com Jovens Aprendizes em uma Empresa Pública Paiva, Jujihara, \& Reis

DOI: http://dx.doi.org/10.21714/2238-104X2017v7i1-3278 Submissão: 09/Fev/2017 - Segunda versão: 11/Abr/2017 - Aceite: 03/Mai/2017

trabalhadores, jovens aprendizes 


\title{
Organizational Values, Work Values and Retalatory Attitudes: a study with young apprentices in a public company
}

\author{
Kely C M Paiva \\ Universidade Federal de Minas Gerais - Brasil \\ kelypaiva@face.ufmg.br \\ Ricardo Ken Fujihara \\ Universidade de Brasília -Brasil \\ ricardowho@gmail.com \\ Jennifer Fernandes Reis \\ Universidade Federal de Minas Gerais - Brasil \\ jenniferfernandesdosreis@hotmail.com
}

\begin{abstract}
In order to analyze how organizational values, work values and retaliatory attitudes of young workers are configured, a case study was carried out in a public company. Data from 508 questionnaires collected throughout the country were analyzed based on univariate and bivariate descriptive statistics. The values "achievement at work" and "achievement in the organization" are the most common among young apprentices addressed, denoting a certain congruence between personal and organizational goals. On the other hand, the pride of the organization is not reflected in the same proportion in relation to the work they actually do, given the differences found between "organizational prestige" and "prestige at work". The position of young people with respect to retaliatory attitudes was predictable, given their adherence to shared values, at both levels, and their little work experience and life in general. The results of the correlation tests were surprising due to their heterogeneity when crossing the themes.
\end{abstract}

Keywords: organizational values, work values, retalatory attitudes, young workers, young apprentices 


\section{Introdução}

O objetivo deste estudo é analisar como se configuram os valores organizacionais, os valores do trabalho e as atitudes retaliatórias de jovens trabalhadores. Tal objetivo advém da percepção de que os valores são crenças relativamente estáveis, associadas a preferências por determinados comportamentos e modos de vida, as quais orientam e justificam as ações, as atitudes e os julgamentos dos indivíduos (Rokeach, 1973). Esta lógica inclui julgamentos, atitudes e ações de natureza contraproducente do ponto de vista da organização, mas que podem reestabelecer a integridade psíquica do indivíduo diante de uma situação que o incomoda, como é o caso de atitudes retaliatórias em face de injustiças observadas no cotidiano laboral, respectivamente.

No nível organizacional, os valores orientam o comportamento dos trabalhadores, ponderando os objetivos coletivos em relação aos individuais (Tamayo, 2005; Tamayo \& Porto, 2005); nesse sentido, eles se amparam nas políticas e nas práticas de gestão da organização, tendo em vista que nem sempre o prescrito é o de fato realizado nesse ambiente (Tamayo, 2005). Além disso, os valores organizacionais associam-se às crenças sobre as metas institucionais compartilhadas pelos que fazem parte da organização (Rokeach, 1973), razão pela qual fornecem um sistema de significados comum que os auxilia a interpretar o ambiente (Rokeach, 1973), inclusive no que tange aos relacionamentos entre as pessoas.

Na esfera do trabalho, os valores constituem um conjunto de crenças que permitem avaliar o que é desejável, ou não, de modo mais específico quanto às atividades que realizam no dia a dia de trabalho, refletindo os desejos e interesses dos trabalhadores (Porto \& Tamayo, 2003; 2008; Porto, 2005).

Assim, em seus diversos campos de análise, os valores pautam as percepções dos indivíduos, inclusive quanto à justiça dentro das organizações. Conceitualmente, quanto mais os valores são comungados, menores são as possibilidades de ocorrerem injustiças e, daí, surgirem sentimentos negativos como as atitudes retaliatórias. Estas atitudes retratam 
uma pré-disposição do indivíduo em retribuir a organização ou seus membros da mesma maneira injusta dispensada a ele próprio ou a terceiros, de modo a reestabelecer um senso de justiça mediante "revanche" (Mendonça \& Tamayo, 2008). Essas atitudes e os comportamentos efetivos que delas derivam são poucos estudados, inclusive no Brasil, em virtude de "sua natureza negativa e a sutileza da sua manifestação" (Mendonça \& Tamayo, 2008, p. 192); no entanto, em outros países, os custos que envolvem ações consideradas negativas, como "roubo, fraude, desvio de dinheiro, vandalismo, sabotagem, absenteísmo e agressão", já têm sido contabilizadas, levando gestores e acadêmicos à sua reflexão (Mendonça \& Tamayo, 2008, p. 191).

Essa reflexão torna-se mais instigante ao se considerar públicos usualmente discriminados nas organizações, devido a diversidades variadas, como cor de pele, gênero, orientação sexual, orientação religiosa, deficiências, e faixa etária, por exemplo (Paiva, Macedo, Irigaray, Dutra, Ferreira, \& Rios, 2015). De fato, "nas organizações, mulheres, negros, obesos, deficientes e gays estão sujeitos a práticas discriminatórias" (Irigaray, 2008, p. 6), as quais são naturalmente percebidas como injustas e, portanto, dignas de retaliação por parte de suas vítimas.

Considerando-se que os jovens trabalhadores são alvos comuns de violência no ambiente de trabalho (Tucker \& Loughlin, 2006; Paiva, Dutra, Barros, \& Santos, 2013), é de se esperar que retribuam de algum modo tais atos, quando considerados injustos. Por outro lado, quanto mais comungam dos valores ali observados, menores as chances de ocorrerem injustiças, ou pelo menos de serem percebidas por eles, e de se desenvolverem atitudes retaliatórias. Note-se que esse grupo de trabalhadores é percebido como uma "população especial” (Barling, Kelloway, \& Frone, 2005; Kelloway, Barling, \& Hurrell, 2006), um caso paradigmático de estudo principalmente em virtude de suas idiossincrasias (Barling et al., 2005; Kelloway et al., 2006; Loughlin \& Lang, 2005; Oliveira, 2011; Paiva, 2012, 2013; Perry \& Parlamis, 2006; Pochmann, 1998; Tucker \& Loughlin, 2006) e dos contextos de trabalhos precários a que normalmente têm acesso (Amorim, 2010; Constanzi, 2009; Loughlin \& Lang, 2005; Oliveira, 2011; Paiva, 2012, 2013; Pochmann, 1998; Tucker \& Loughlin, 2006), sob os quais têm se observado avanços em termos de diminuição da qualidade de vida no trabalho (Rios, Paiva, Rocha, \& Ferreira, 2015) e processos de insatisfação, podendo chegar ao desenvolvimento de quadros de síndrome burnout (Souza, Helal, \& Paiva, 2016). 
No entanto, no Brasil, a Lei do Aprendiz, Decreto $n^{\circ}$ 5.598/2005, que trata da inserção e do trabalho de jovens entre 14 e 17 anos, detalha as atividades laborais que tal público pode desenvolver, assim como as condições de trabalho a serem oferecidas pelas organizações que os contratam. Essa legislação atenta para o aprimoramento do jovem no ambiente de trabalho, obrigando-os a frequentar cursos e programas de aprendizagem. Assim sendo, várias organizações têm contratado jovens trabalhadores, concedendo-lhes oportunidades laborais em tais condições consideradas distintas das demais, inclusive do que diz respeito ao "trabalho infantil". Este é o caso da empresa pública abordada neste estudo, a qual oferece vagas destinadas à contratação especial de aprendizes.

Note-se que este estudo tem aderência às recomendações de outros trabalhos sobre os temas relativos aos valores no ambiente organizacional (Ferreira, Fernandes \& Silva, 2009; Oliveira \& Tamayo, 2004; Paiva, 2012, 2013; Porto \& Tamayo, 2003, 2008; Tamayo, 2008) e às atitudes retaliatórias (Franco \& Nilles, 2016; Franco \& Paiva, 2016; Mendonça \& Tamayo, 2008; Paiva \& Leite, 2011), assim como sobre os jovens trabalhadores (Franco \& Nilles, 2016; Franco \& Paiva, 2016; Oliveira, 2011; Paiva, 2012, 2013; Paiva et al., 2013; Paiva \& Souza, 2016; Rios et al., 2015; Souza, Helal, \& Paiva, 2016). Desse modo, estas temáticas têm sido estudadas no país; no entanto, com a forma integrada aqui apresentada não foram encontrados precedentes, preenchendo-se, portanto, uma lacuna nos estudos do campo do comportamento organizacional.

Para tanto, este artigo foi estruturado da seguinte forma: após esta introdução, seguem-se referências conceituais dos temas centrais do estudo e a metodologia empregada na pesquisa empírica. Na sequência, os dados são apresentados e analisados, permitindo o delineamento das considerações finais. A lista de referências encerra o artigo.

\section{Referencial Teórico}

Para fins desse estudo, os valores organizacionais são compreendidos como crenças que pautam o dia a dia da organização e de seus membros, considerando interesses individuais e/ou coletivos (Mendes \& Tamayo, 1999; Porto, 2005). Por meio deles, os indivíduos podem reconhecer a realidade organizacional, vivenciada nos âmbitos formal e informal (Tamayo \& Porto, 2005). São, portanto, elementos estruturantes da vida 
organizacional, pois norteiam o trabalho e o cotidiano das organizações, de modo que interesses coletivos se sobreponham aos individuais (Tamayo, 2005; Tamayo \& Porto, 2005).

Essa sobreposição perde efeito, ou mesmo pode ter consequências contrárias, se os valores formais da organização não são percebidos no seu dia a dia pelos trabalhadores, ou seja, não são comungados no cotidiano laboral, prejudicando a relação entre tais agentes sociais (Tamayo, 2005). Note-se que isso é muito comum no interior de empresas, já que são demandadas características pessoais contraditórias ao trabalhador, como, por exemplo: que sejam inovadores, mas sigam as normas; que sejam participativos, mas promovam o consenso e se atenham ao projeto da organização; que sejam cooperativos, mas não se esqueçam de suas metas individuais (e individualizantes), dentre outros (Lima, 1995).

Assim sendo, é natural que as organizações busquem pessoas cada vez mais jovens para compor seus quadros, pois esse estágio precoce de desenvolvimento da personalidade facilita sua adesão à filosofia ali vigente, inclusive no que diz respeito à racionalização das referidas contradições. (Lima, 1995)

No entanto, são escassos na literatura modelos analíticos para compreensão dos valores organizacionais, bem como instrumentos de diagnóstico específicos relativos à sua mensuração (Tamayo, 2008).

No Brasil, três instrumentos dessa natureza foram validados e usados em pesquisas sobre a temática. O primeiro deles foi a Escala de Valores Organizacionais, EVO, validada por Tamayo e Gondim (1996); o segundo foi validado por Tamayo, Mendes e Paz (2000), o Inventário de Valores Organizacionais, IVO; por fim, a terceira escala foi validada por Oliveira e Tamayo (2004) e chama-se Inventário de Perfis de Valores Organizacionais (IPVO). (Paiva, 2012, p. 5)

Este Inventário de Perfis de Valores Organizacionais (IPVO) é composto por oito valores pautados nos tipos motivacionais da Teoria de Valores de Schwartz (2008), descritos da seguinte maneira (Oliveira \& Tamayo, 2004, p. 137):

(1) Autonomia: "oferecer desafios e variedade no trabalho, estimular a curiosidade, a 
criatividade e a inovação";

(2) Bem-estar: "promover a satisfação, o bem-estar e a qualidade de vida no trabalho";

(3) Realização: "valorizar a competência e o sucesso dos trabalhadores";

(4) Domínio: "obter lucros, ser competitiva e dominar o mercado";

(5) Prestígio: "ter prestígio, ser conhecida e admirada por todos, oferecer produtos e serviços satisfatórios para os clientes";

(6) Tradição: "manter a tradição e respeitar os costumes da organização";

(7) Conformidade: "promover a correção, a cortesia e as boas maneiras no trabalho e o respeito às normas da organização";

(8) Preocupação com a coletividade: "promover a justiça e a igualdade na organização, bem como a tolerância, a sinceridade e a honestidade".

Em pesquisa realizada no Brasil com jovens trabalhadores, observou-se a preponderância dos valores Realização e Conformidade, sendo Bem-Estar e Tradição os menos comungados pelos abordados (Paiva, 2012, 2013), o que reflete a preferência das organizações em contratar profissionais cada vez mais jovens, já que é notória sua influência nos valores e comportamentos de trabalhadores neófitos no mundo laboral (Lima, 1995).

Outro tema abordado neste estudo refere-se aos valores do trabalho, ou seja, crenças sobre o que é desejável, ou não, no trabalho, que espelham interesses das pessoas e são avaliadas de acordo com a importância atribuída a cada um deles (Porto \& Tamayo, 2003, 2008; Porto, 2005). De modo mais detalhado, pode-se compreender esses valores no âmbito do trabalho como um conjunto de crenças sobre aquilo que é desejável ou não no trabalho (natureza cognitiva do construto), que refletem desejos e interesses dos indivíduos (natureza motivacional) e que são avaliados conforme a relevância atribuída a cada um deles, que varia ao longo de um contínuo de importância (natureza hierárquica) (Porto \& Tamayo, 2003; 2008; Porto, 2005).

Importante destacar o papel central do trabalho na vida das pessoas na atualidade (Tamayo \& Borges, 2006; Porto \& Tamayo, 2008) e que ele também contribui na construção da identidade dos sujeitos (Porto \& Tamayo, 2008), em diversos níveis (Machado, 2003).

No Brasil, foram desenvolvidas e validadas duas escalas relativas aos valores do trabalho: “(...) a primeira foi o Inventário de Significado do Trabalho (IST), desenvolvido por 
Borges (1999); a segunda escala validada chama-se Escala de Valores relativos ao Trabalho (EVT), construída e validada por Porto e Tamayo (Porto; Tamayo, 2003; 2008; Porto, 2005) (...)". (Paiva, 2012, p. 6)

Pautando-se na Teoria de Valores de Schwartz (2008), a Escala de Valores relativos ao Trabalho (EVT) considera quatro valores, descritos da seguinte forma (Porto \& Tamayo, 2003, p. 151; Porto, 2005, pp. 112-113):

(1) Realização: que diz de abertura a mudança (Schwartz, 2008) e destaca a "mudança por meio do trabalho autônomo e criativo";

(2) Relações Sociais: que reflete autotranscendência (Schwartz, 2008) e focaliza a “relacionamento social positivo favorecendo o bem-estar das pessoas próximas e da sociedade";

(3) Prestígio: relativo à autopromoção (Schwartz, 2008) e privilegiando "metas de sucesso pessoal e influência sobre os outros";

(4) Estabilidade: relacionada a conservação (Schwartz, 2008) e sublinha a "segurança e manutenção do status quo por meio do trabalho".

Dados de pesquisa com jovens brasileiros indicaram a preponderância dos valores Realização no Trabalho e Estabilidade (Campos, 2008; Paiva, 2012, 2013) em detrimento de Prestígio (Paiva, 2012, 2013), espelhando como produtividade e segurança são mais valorizadas que o tipo de atividade produtiva em si realizada por tais trabalhadores, rotineiras e repetitivas, características comuns no início de carreira.

Por fim, as atitudes retaliatórias são analisadas neste estudo à luz de dois componentes, quais sejam: o afetivo, que diz respeito ao nível de indignação do sujeito face à situação percebida como injusta, o qual pode levar ao ressentimento, à decepção e ao desprezo; e o conativo, relativo à tendência que o indivíduo tem de comportar-se, de modo consciente, de maneira semelhante à organização ou seu(s) membro(s), retribuindo a justiça recebida com atos positivos e a injustiça com ações negativas, deletérias do ponto de vista de seus alvos (organização ou seus membros) (Mendonça, Flauzino, \& Tamayo, 2004a).

Mesmo diante de uma injustiça, o trabalhador pode optar por não retaliar, haja vista a ocorrência de processos de conformação e racionalização que justifiquem tal resignação em situações dessa natureza, como já observado em pesquisa com jovens trabalhadores brasileiros (Franco \& Nilles, 2016). Por outro lado, em contextos de vulnerabilidade de 
diversas ordens, jovens trabalhadores podem perceber seu contexto de trabalho como menos precário e mais profissional do que normalmente é apreendido por outros sujeitos não assistidos por instituições de formação profissional (Franco \& Paiva, 2016), ou seja, fora dos ditames da mencionada Lei do Aprendiz (Brasil, 2015).

Para mensurá-los, Mendonça \& Tamayo (2003) desenvolveram e validaram a Medida de Atitude em Relação à Retaliação Organizacional, MARO. Além desta, Mendonça, Flauzino, Tamayo \& Paz (2004b) desenvolveram e validaram a Escala de Percepção e Julgamento da Retaliação, EPJR, com o objetivo de avaliar a frequência da retaliação e as dimensões perceptivas e avaliativas desse comportamento. No Brasil, desconhece-se outras escalas para estudo das atitudes retaliatórias.

Além da já citada recenticidade dessas escalas e seu desenvolvimento considerando-se aspectos peculiares à cultura nacional, elas têm sido aplicadas em outros estudos, o que facilita comparação de dados, inclusive os que abordam jovens trabalhadores, como os citados anteriormente.

\section{Metodologia}

Visando o objetivo deste estudo, foi realizada uma pesquisa de campo, descritiva, nos moldes de um estudo de caso, com abordagem quantitativa (Vergara, 2009). O caso abordado foi uma organização pública que se constitui como uma das maiores empregadoras do país, com mais de 120 mil trabalhadores, dentre eles cerca de 5 mil jovens aprendizes, espalhados por todo território nacional. Devido a essas características da empresa e à autorização formal da diretoria responsável pelo programa de jovem aprendiz, em Brasília (DF), o critério de acessibilidade (Vergara, 2009) foi considerado no nível da organização.

Para a coleta de dados, a população de jovens aprendizes informada pela referida diretoria foi de 4.857 trabalhadores. O cálculo amostral indicou uma amostra mínima de 370 respondentes, levando-se em conta 95\%de confiabilidade e 5\% de margem de erro. A amostragem foi aleatória (probabilística) (Cooper \& Schindler, 2008), realizada por meio de divulgação via e-mail para os jovens, com a disponibilização de um link para preenchimento do questionário "virtual”. Retornaram 633 questionários dentre os quais 508 preenchidos 
adequadamente, sendo este o quantitativo da amostra final da pesquisa. O questionário foi composto de sete partes, a saber:

(1) dados sócio-demográficos e profissionais dos respondentes;

(2) Inventário de Perfis de Valores Organizacionais, IPVO (Tamayo, 2008);

(3) Escala de Valores relativos ao Trabalho, EVT (Porto \& Tamayo, 20o8);

(4) Escala de Percepção e Julgamento da Retaliação Organizacional (EPJR) e Medida de Atitude em Relação à Retaliação Organizacional (MARO) (Mendonça, 2008);

(5) Escala de Percepções Temporais, EPT (Paiva et al., 2013), esclarecendo-se que os dados dessa parte não foram incluídos neste artigo;

(6) Pergunta sobre o nível de satisfação do jovem com a organização;

(7) Espaço para dúvidas, comentários e sugestões.

Para análise de dados, eles foram todos inseridos em uma planilha eletrônica (Excel 97/2003, SPSS), tabulados e analisados por meio de estatística descritiva uni (medidas de posição e dispersão; percentuais de respondentes por nível de análise das variáveis) e bivariada (teste de correlação não paramétrico - Pearson -, tendo em vista que os dados violaram as condições de normalidade, conforme apontado no resultado do teste Kolmorov Smirnov).

\section{Apresentação e Discussão dos Dados}

Dentre os 508 respondentes do questionário, preponderaram: mulheres $(68,7 \%)$; com 16 anos de idade (37,0\%); solteiros (96,9\%); com ensino médio incompleto (53,1\%); pais com ensino fundamental incompleto (36,4\%); mães com ensino médio completo (35,6\%); possui tempo total de trabalho de 6 meses a 1 ano $(56,7 \%)$, sendo este também o período predominante de trabalho na organização $(73,8 \%)$; com renda familiar variando entre 1 e 2 salários mínimos (49,4\%). Esses dados são semelhantes aos apresentados por Paiva (2013), à exceção de renda familiar, pois a faixa de renda predominante encontrada pela autora foi entre 1 e 4 salários mínimos; em ambos os casos, a importância da renda dos jovens trabalhadores na composição da renda familiar é inegável. Além disso, a maior parte dos respondentes foi da região sudeste (53,3\%), em especial do estado de São Paulo (43,5\%), seguidos da região nordeste $(18,1 \%)$, com destaque para Bahia $(6,1 \%)$, e centro-oeste $(15,6 \%)$, 
preponderando respondentes do Distrito Federal (8,1\%).

Em relação aos valores organizacionais, pautando-se no modelo analítico adotado (Oliveira \& Tamayo, 2004; Tamayo, 2008), a maioria dos jovens aprendizes apresentou médias elevadas (acima de 3,0), indicando que eles comungam desses valores considerados importantes por eles próprios. (Tabela 1)

Tabela 1

Valores organizacionais dos jovens aprendizes: medidas descritivas e percentuais de respondentes por níveis de percepção

\begin{tabular}{|c|c|c|c|c|c|c|c|c|}
\hline \multirow[b]{2}{*}{$\begin{array}{c}\text { Valores } \\
\text { Organizaciona } \\
\text { is }\end{array}$} & \multicolumn{5}{|c|}{ Medidas descritivas } & \multicolumn{3}{|c|}{ Percentuais de respondentes } \\
\hline & Média & $\begin{array}{l}\text { Desvio } \\
\text { Padrão }\end{array}$ & $\mathbf{P}_{25}$ & Mediana & $\mathbf{P}_{75}$ & $\begin{array}{c}\text { Forte, } \\
\text { importante, } \\
\text { elevado } \\
(\text { média }>= \\
3,0)\end{array}$ & $\begin{array}{c}\text { Mediano } \\
\text { (média } \\
\text { entre } 2,0 \text { e } \\
3,0)\end{array}$ & $\begin{array}{c}\text { Frágil, nada } \\
\text { importante, } \\
\text { baixo } \\
(\text { média }=< \\
2,0)\end{array}$ \\
\hline Realização & 4,1 & 0,9 & 3,6 & 4,2 & 4,8 & 89,8 & 7,9 & 2,4 \\
\hline Conformidade & 4,1 & 0,7 & 3,6 & 4,1 & 4,7 & 92,7 & 6,1 & 1,2 \\
\hline Prestígio & 4,0 & 0,9 & 3,5 & 4,3 & 4,8 & 89,2 & 8,3 & 2,6 \\
\hline $\begin{array}{l}\text { Preocupação } \\
\text { com a } \\
\text { coletividade }\end{array}$ & 4,0 & 0,9 & 3,7 & 4,3 & 4,7 & 89,2 & 8,1 & 2,8 \\
\hline Autonomia & 3,6 & 1,0 & 3,0 & 3,8 & 4,4 & 77,5 & 14,8 & 7,7 \\
\hline Domínio & 3,5 & 0,9 & 2,8 & 3,7 & 4,3 & 72,4 & 20,9 & 6,7 \\
\hline Tradição & 3,4 & 1,0 & 2,8 & 3,4 & 4,0 & 74,6 & 17,9 & 7,5 \\
\hline Bem-estar & 3,3 & 1,1 & 2,7 & 3,5 & 4,2 & 68,9 & 18,1 & 13,0 \\
\hline
\end{tabular}

Nota. Fonte: Dados da pesquisa.

Os valores "realização" e "conformidade" obtiveram as maiores médias $(4,1)$, corroborando achados (Paiva, 2012, 2013) e proposições (Lima, 1995) de pesquisas anteriores, no que diz respeito ao fato de as organizações terem facilidade de moldar valores e comportamentos de trabalhadores mais jovens, o que justifica sua contratação. Os valores considerados menos importantes, mas ainda em níveis elevados, foram "tradição" e "bemestar" (médias 3,4 e 3,3, respectivamente), o que também foi encontrado em outros estudos (Paiva, 2012, 2013), o que pode reforçar a ideia acerca da pouca preocupação quanto à manutenção de costumes e demais práticas da organização, já que trata-se de sua primeira experiência de trabalho e, ainda, com pouco tempo nele. Os dados relativos ao bem-estar ensejam outras pesquisas, pois usualmente indicam condições de trabalho precárias (Constanzi, 2009; Loughlin \& Lang, 2005; Pochmann, 1998; Tucker \& Loughlin, 2006; Paiva, 
2012, 2013), fato que se choca com o nível de satisfação com a empresa manifesto pelos jovens na pesquisa. Observem-se os dados: o,6\% do total responderam estar muito insatisfeito; $1,0 \%$ insatisfeito; $7,5 \%$ mais ou menos satisfeito; $27,6 \%$ satisfeito; e $63,4 \%$ muito satisfeito; ou seja, 91,0\% deles assinalaram estar satisfeitos e muito satisfeitos; estes dados contradizem dados observados em outras pesquisas no Brasil (Souza, Helal, \& Paiva, 2016). Considerando-se o percentual de respondentes por nível de avaliação desses valores, dois números chamam a atenção: o primeiro, refere-se a 20,9\% dos jovens que consideram “domínio” um valor mediano, o que pode ser explicado pelo avanço de tecnologias de comunicação e transporte que podem estar afetando os negócios da organização, ou seja, tais tecnologias têm impacto direto nos produtos e serviços comercializados pela empresa, daí essa percepção por parte dos respondentes. $O$ segundo ponto relaciona-se aos percentuais de "bem estar" que, de modo geral, reforçam a dúvida quanto às condições de trabalho a que os jovens estão submetidos, já que 18,1\% o consideram mediano e 13,0\% frágil, baixo ou nada importante no seu espaço laboral. Esses dados, portanto, trazem suspeitas em termos de sua qualidade de vida no trabalho, avaliada como mediana e em queda em outro estudo, de caráter longitudinal, com público semelhante ao aqui abordado (Rios et al., 2015), assim como de seu comprometimento, percebido como mediano nas dimensões calculativa e normativa pela maioria dos respondentes em pesquisa com jovens trabalhadores, também semelhantes aos abordados nesta pesquisa (Rocha \& Paiva, 2016).

Os valores do trabalho dos respondentes, considerando-se o modelo analítico adotado (Porto \& Tamayo, 2003, 2008; Porto, 2005), também se apresentaram com médias elevadas (acima de 3,5), à exceção do valor “prestígio” (média de 3,1). (Tabela 2)

Tabela 2

Valores do Trabalho dos jovens aprendizes: medidas descritivas e percentuais de por níveis de percepção

\begin{tabular}{|c|c|c|c|c|c|c|c|c|}
\hline & \multicolumn{5}{|c|}{ Medidas descritivas } & \multicolumn{3}{|c|}{ Percentuais de respondentes } \\
\hline $\begin{array}{l}\text { Valores do } \\
\text { Trabalho }\end{array}$ & Média & $\begin{array}{l}\text { Desvio } \\
\text { Padrão }\end{array}$ & $\mathbf{P}_{25}$ & Mediana & $\mathbf{P}_{75}$ & \begin{tabular}{|c|} 
Forte, \\
importante, \\
elevado \\
(média $>=$ \\
3,5)
\end{tabular} & $\begin{array}{c}\text { Mediano } \\
\text { (média } \\
\text { entre } 2,5 \text { e } \\
\text { 3,5) }\end{array}$ & \begin{tabular}{|c} 
Frágil, nada \\
importante, \\
baixo \\
(média $=<$ \\
$2,5)$
\end{tabular} \\
\hline
\end{tabular}




\begin{tabular}{lc|ccccc|ccc}
\hline $\begin{array}{l}\text { Realização } \\
\text { trabalho }\end{array}$ & no & 4,2 & 0,6 & 3,9 & 4,3 & 4,6 & 87,2 & 12,2 & 0,6 \\
Estabilidade & 4,1 & 0,7 & 3,7 & 4,3 & 4,7 & 79,3 & 18,9 & 1,8 & \\
Relações Sociais & 4,1 & 0,6 & 3,7 & 4,2 & 4,7 & 83,1 & 15,7 & 1,2 & \\
Prestígio & 3,1 & 0,8 & 2,6 & 3,1 & 3,6 & 31,3 & 46,9 & 21,9 \\
\hline
\end{tabular}

Nota. Fonte: Dados da pesquisa.

O resultado do valor do trabalho "prestígio" pode estar refletindo a natureza e o conteúdo empobrecido do trabalho realizado pelos jovens aprendizes, o que é natural quando se está adentrando no mercado de trabalho, em estágios iniciais de carreira, corroborando dados de outras pesquisas (Paiva, 2012, 2013). Já os resultados do valor "realização no trabalho" e "estabilidade" denotam prazer e realização pessoal e profissional desses jovens, estímulo e independência de pensamento e ação no trabalho por meio da autonomia intelectual e da criatividade, são aspectos considerados importantes pela amostra, assim como segurança e estabilidade financeira, respectivamente (Porto \& Tamayo, 2003, 2008; Porto, 2005). De modo semelhante a outros achados (Paiva, 2012, 2013), os jovens abordados nesta pesquisa também apresentaram o valor "relações sociais" de modo mais tímido, o que amplia as dúvidas em relação à ampla rede de relacionamentos e à intensa vida social típicas dessa faixa etária. Os percentuais de respondentes por nível de percepção dos valores do trabalho reforçam as inferências anteriores.

Já os resultados relativos às atitudes retaliatórias, considerando-se os padrões analíticos adotados (Mendonça \& Tamayo, 2003; Mendonça et al., 2004b), estão dispostos na Tabela 3.

Tabela 3

Medidas descritivas e Percentuais de respondentes da amostra, por aspectos de retaliação e seus níveis de percepção

\begin{tabular}{l|c|c|c|c|c|c|c|c}
\hline \multirow{2}{*}{$\begin{array}{c}\text { Atitudes } \\
\text { Retaliatórias }\end{array}$} & \multicolumn{4}{|c|}{ Medidas Descritivas } & \multicolumn{2}{c}{$\begin{array}{c}\text { Percentuais de respondentes por níveis } \\
\text { de concordância }\end{array}$} \\
\cline { 2 - 9 } & Média & $\begin{array}{c}\text { Desvio- } \\
\text { Padrão }\end{array}$ & $\mathbf{P}_{25}$ & Mediana & $\mathbf{P}_{75}$ & média $>=3,0$ & $\begin{array}{c}\text { média entre } \\
2,0 \text { e 3,0 }\end{array}$ & média =<2,0 \\
\hline Percepção & 1,6 & 0,8 & 1,1 & 1,3 & 1,9 & Sempre & Duvidoso & Nunca \\
\hline Julgamento & 1,7 & 0,7 & 1,2 & 1,6 & 2,0 & Justíssimo & Duvidoso & Muito injusto \\
\hline
\end{tabular}




\begin{tabular}{|c|c|c|c|c|c|c|c|c|}
\hline & & & & & & 6,3 & 15,9 & 77,8 \\
\hline \multirow{2}{*}{$\begin{array}{l}\text { Componente } \\
\text { Afetivo }\end{array}$} & \multirow[t]{2}{*}{3,1} & \multirow[t]{2}{*}{1,0} & \multirow[t]{2}{*}{2,4} & \multirow[t]{2}{*}{3,1} & \multirow[t]{2}{*}{3,9} & Indignação & $\begin{array}{l}\text { Sentimento } \\
\text { ambivalente }\end{array}$ & $\begin{array}{c}\text { Não } \\
\text { indignação }\end{array}$ \\
\hline & & & & & & 59,1 & 24,6 & 16,3 \\
\hline \multirow[t]{2}{*}{$\begin{array}{l}\text { Componente } \\
\text { Conativo }\end{array}$} & \multirow{2}{*}{1,7} & \multirow{2}{*}{0,8} & \multirow{2}{*}{1,0} & \multirow{2}{*}{1,4} & \multirow{2}{*}{2,2} & $\begin{array}{c}\text { Propensão } \\
\text { a retaliar }\end{array}$ & $\begin{array}{c}\text { Reação } \\
\text { duvidosa }\end{array}$ & $\begin{array}{l}\text { Propensão a } \\
\text { não retaliar }\end{array}$ \\
\hline & & & & & & 10,8 & 15,7 & 73,4 \\
\hline
\end{tabular}

Nota. Fonte: Dados da pesquisa.

Esses dados indicam que a maioria dos jovens aprendizes abordados fica indignada com injustiças percebidas $(59,1 \%$ deles $)$ e não é propensa a retaliar ( $73,4 \%$ deles); a maioria nunca nota ações de retaliação às injustiças $(78,5 \%$ deles) e julga muito injusto quando isso (retaliações) ocorre $(77,8 \%$ deles) , semelhante a outros estudos (Franco \& Nilles, 2016; Franco \& Paiva, 2106), o que pode denotar significativo comprometimento de sua parte com a organização pública abordada, fato também observados em pesquisa anteriores (Rocha \& Paiva, 2016).

Por fim, os resultados dos testes de correlação indicaram relações positivas ( $r$ o positivo) e significativas ( $\mathrm{p}$-valor menor que 0,05 , destacado em negrito na Tabela 4) de todos os valores entre si, ou seja, há uma relação direta no julgamento dos valores organizacionais e do trabalho por parte dos jovens abordados. Já as relações entre valores e atitudes retaliatórias não se comportaram de modo uniforme, como pode-se observar na Tabela 4 .

Tabela 4

Resultados dos testes de correlação

\begin{tabular}{|c|c|c|c|c|c|c|c|c|c|c|c|c|c|c|c|c|}
\hline & \multicolumn{8}{|c|}{ Valores Organizacionais ${ }^{(1)}$} & \multicolumn{4}{|c|}{ Valores do Trabalho ${ }^{(2)}$} & \multicolumn{4}{|c|}{$\begin{array}{c}\text { Atitudes } \\
\text { Retaliatórias }^{(3)}\end{array}$} \\
\hline & A & BE & RO & D & PO & C & $\mathrm{T}$ & PC & RT & RS & PT & $\mathbf{E}$ & $\mathbf{P}$ & $\mathbf{J}$ & CA & $\mathrm{CC}$ \\
\hline$\overline{\mathrm{BE}}$ & $\begin{array}{l}, 803 \\
, 000\end{array}$ & * & * & * & * & * & * & * & * & * & * & * & * & $*$ & * & $*$ \\
\hline RO & $\begin{array}{l}, 809 \\
, 000\end{array}$ & $\begin{array}{l}, 662 \\
, 000\end{array}$ & $*$ & * & * & * & $*$ & * & * & * & * & * & * & $*$ & * & $*$ \\
\hline D & $\begin{array}{l}, 591 \\
, \mathbf{0 0 0}\end{array}$ & $\begin{array}{l}, 570 \\
, \mathbf{0 0 0}\end{array}$ & $\begin{array}{l}, 537 \\
\text {,ooo }\end{array}$ & * & * & * & $*$ & * & * & * & * & * & * & $*$ & * & * \\
\hline PO & $\begin{array}{l}, 676 \\
\text {,ooo }\end{array}$ & $\begin{array}{l}, 606 \\
, 000\end{array}$ & $\begin{array}{l}, 689 \\
\text {,ooo }\end{array}$ & $\begin{array}{l}, 635 \\
, 000\end{array}$ & * & * & $*$ & * & * & * & * & * & * & $*$ & * & $*$ \\
\hline C & $\begin{array}{l}, 680 \\
, 000\end{array}$ & $\begin{array}{l}, 559 \\
, \mathbf{0 o 0}\end{array}$ & $\begin{array}{l}, 765 \\
, \mathbf{o o o}\end{array}$ & $\begin{array}{l}, 584 \\
, \mathbf{0 0 0}\end{array}$ & $\begin{array}{l}, 691 \\
, 000\end{array}$ & * & $*$ & * & * & * & * & * & $*$ & $*$ & * & * \\
\hline
\end{tabular}




\begin{tabular}{|c|c|c|c|c|c|c|c|c|c|c|c|c|c|c|c|c|}
\hline $\mathbf{T}$ &, 565 & ,541 &, 558 &, 565 &, 561 & ,673 & * & * & * & * & * & * & * & * & * & * \\
\hline & ,оOо & ,оoo & , 000 & , 000 & , 000 & , 000 & & & & & & & & & & \\
\hline PC &, 767 & ,698 & ,795 & ,456 & ,642 &, 740 &, 539 & * & * & * & * & * & * & * & * & * \\
\hline & ,000 & ,000 & ,000 & ,000 & ,000 & ,000 & , 000 & & & & & & & & & \\
\hline RT & ,331 & ,296 & ,338 & ,377 & ,345 & ,359 & ,269 & ,257 & * & * & * & * & * & * & * & * \\
\hline & ,оoo & , & ,000 & ,000 & , 000 & ,000 & , & ,ooo & & & & & & & & \\
\hline RS & ,369 & ,333 & 344 & 342 & ,357 & 379 & 296 & ,298 & ,763 & * & * & * & * & * & * & * \\
\hline & ,оoo & , & , & , & , & , & , & ,ooo & ,000 & & & & & & & \\
\hline PT & ,329 & ,309 & 277 & ,405 & 277 & ,273 & ,312 & 178 & ,649 & ,601 & * & * & * & * & * & * \\
\hline & , & , & , & , & ,о00 & ,000 & , & , & ,000 & ,ooo & & & & & & \\
\hline $\mathbf{E}$ & 186 & 141 & 192 &, 352 & ,289 & ,241 & ,225 & 128 & ,663 & ,530 & ,546 & * & * & * & * & * \\
\hline & ,ooo & ,001 & , 000 & ,000 & ,000 & , 000 & , 000 &, 004 & , 000 & , $\mathbf{0 0 0}$ & , 000 & & & & & \\
\hline $\mathbf{P}$ &,- 250 &,- 275 &,- 212 &,- 037 &,- 101 &,- 146 &,- 051 &,- 322 & ,065 &,- 004 & ,062 & 182 & * & * & * & * \\
\hline & ,ooo & ,ooo & , 000 & 411 & ,023 & ,001 & ,253 & , $\mathbf{0 0 0}$ & 146 & ,934 & 164 & ,000 & & & & \\
\hline $\mathbf{J}$ &,- 161 &,- 151 &,- 175 &,- 076 &,- 126 &,- 170 &,- 111 &,- 230 &,- 173 &,- 212 &,- 040 &,- 055 & ,427 & * & * & * \\
\hline & ,ooo & , 001 & ,ooo & ,o86 & ,004 & ,оoo & , 012 & , $\mathbf{0 0 0}$ & , & ,ooo &, 363 & ,216 & , & & & \\
\hline CA &,- 121 &,- 104 &,- 077 & , 011 &,- 075 &,- 050 &,- 028 &,- 074 &,- 013 &,- 047 & ,o69 & , 105 & ,o79 & 117 & * & * \\
\hline & ,006 & ,019 & ,081 & ,811 & ,091 & , 256 &, 527 & ,098 & ,764 & 288 & 120 & ,018 & , O74 &, 008 & & \\
\hline $\mathrm{CC}$ &,- 087 &,- 057 &,- 163 & , 041 &,- 148 &,- 136 & ,015 &,- 215 &,- 069 &,- 098 & 113 & , 047 & 177 & ,266 & ,377 & $*$ \\
\hline & , 049 & ,202 & , $\mathbf{0 0 0}$ &, 352 & ,001 &, 002 & ,743 & , $\mathbf{0 0 0}$ & ,120 & ,027 & , 011 & ,288 & , & , 000 & , 000 & \\
\hline & & & alores & Orga & nizaci & onais & & & Valor & es do & Traba & lho ${ }^{(2)}$ & & $\begin{array}{l}\text { Ati } \\
\text { etali }\end{array}$ & $\begin{array}{l}\text { des } \\
\text { Orias }\end{array}$ & \\
\hline & A & BE & RO & D & PO & C & $\mathbf{T}$ & PC & RT & RS & PT & $\mathbf{E}$ & $\mathbf{P}$ & $\mathbf{J}$ & CA & $\mathrm{CC}$ \\
\hline
\end{tabular}

Nota: (1) Valores Organizacionais: RO - Realização; C - Conformidade; PO - Prestígio; PC Preocupação com a coletividade; A - Autonomia; D - Domínio; T - Tradição; BE - Bemestar; (2) Valores do Trabalho: RT - Realização no trabalho; E - Estabilidade; RS - Relações Sociais; PT - Prestígio; (3) Atitudes Retaliatórias: P - Percepção; J - Julgamento; CA Componente Afetivo; CC - Componente Conativo. Fonte: Dados da pesquisa.

O único valor que apresentou um comportamento homogêneo (rho negativo e p-valor abaixo de o,05) em relação às variáveis de atitudes retaliatórias foi o valor organizacional "autonomia".

A esse respeito, pode-se afirmar que, à medida que aumenta a avaliação do jovem quanto à autonomia compartilhada na organização, diminuem (1) sua tendência de ficar indignado com injustiças percebidas, (2) sua propensão a retaliar, (3) sua possibilidade de notar ações de retaliação às injustiças e (4) sua possibilidade de julgar como injustas as retaliações observadas.

Com vistas a sintetizar os resultados da pesquisa, elaborou-se o Quadro 1, no qual constam os principais resultados da pesquisa. 


\begin{tabular}{|c|c|c|c|c|}
\hline \multirow[t]{2}{*}{ Tema } & \multirow[t]{2}{*}{ Variáveis } & \multirow[t]{2}{*}{ Resultado } & \multicolumn{2}{|r|}{ Correlações } \\
\hline & & & Comuns & Diferenciadas \\
\hline \multirow{8}{*}{ 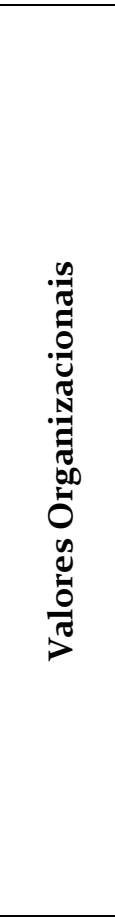 } & Realização & \multirow{8}{*}{$\begin{array}{l}\text { Forte, } \\
\text { importante } \\
\text {, elevado }\end{array}$} & \multirow{8}{*}{$\begin{array}{c}\text { Significativas e diretas } \\
\text { (positivas) com todos os } \\
\text { demais valores } \\
\text { organizacionais e com todos } \\
\text { os valores do trabalho }\end{array}$} & $\begin{array}{l}\text { Significativa e direta com a maioria das } \\
\text { variáveis de atitudes retaliatórias } \\
\text { (exceção: Componente afetivo) }\end{array}$ \\
\hline & $\begin{array}{c}\text { Conformidad } \\
\mathrm{e}\end{array}$ & & & $\begin{array}{l}\text { Significativa e direta com a maioria das } \\
\text { variáveis de atitudes retaliatórias } \\
\text { (exceção: Componente afetivo) }\end{array}$ \\
\hline & Prestígio & & & $\begin{array}{l}\text { Significativa e direta com a maioria das } \\
\text { variáveis de atitudes retaliatórias } \\
\text { (exceção: Componente afetivo) }\end{array}$ \\
\hline & $\begin{array}{l}\text { Preocupação } \\
\text { com a } \\
\text { coletividade }\end{array}$ & & & $\begin{array}{l}\text { Significativa e direta com a maioria das } \\
\text { variáveis de atitudes retaliatórias } \\
\text { (exceção: Componente afetivo) }\end{array}$ \\
\hline & Autonomia & & & $\begin{array}{c}\text { Significativa e direta com todas as variáveis } \\
\text { de atitudes retaliatórias }\end{array}$ \\
\hline & Domínio & & & $\begin{array}{c}\text { Não significativa com todas as variáveis de } \\
\text { atitudes retaliatórias }\end{array}$ \\
\hline & Tradição & & & $\begin{array}{c}\text { Significativa e direta apenas com o } \\
\text { Julgamento das atitudes retaliatórias }\end{array}$ \\
\hline & Bem-estar & & & $\begin{array}{l}\text { Significativa e direta com a maioria das } \\
\text { variáveis de atitudes retaliatórias } \\
\text { (exceção: Componente conativo) }\end{array}$ \\
\hline \multirow{4}{*}{ 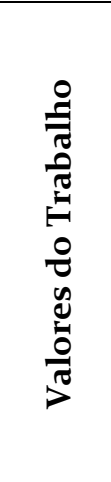 } & $\begin{array}{l}\text { Realização no } \\
\text { trabalho }\end{array}$ & \multirow{3}{*}{$\begin{array}{l}\text { Forte, } \\
\text { importante, } \\
\text { elevado }\end{array}$} & \multirow{4}{*}{$\begin{array}{l}\text { Significativas e diretas } \\
\text { (positivas) com todos os } \\
\text { demais valores do trabalho e } \\
\text { com todos os valores } \\
\text { organizacionais }\end{array}$} & $\begin{array}{l}\text { Significativa e direta apenas com o } \\
\text { Julgamento das atitudes retaliatórias }\end{array}$ \\
\hline & Estabilidade & & & $\begin{array}{c}\text { Significativa e direta apenas com a Percepção } \\
\text { e o Componente afetivo das atitudes } \\
\text { retaliatórias }\end{array}$ \\
\hline & $\begin{array}{l}\text { Relações } \\
\text { Sociais }\end{array}$ & & & \begin{tabular}{|c|} 
Significativa e direta apenas com o \\
Julgamento e o Componente conativo das \\
atitudes retaliatórias
\end{tabular} \\
\hline & Prestígio & Mediano & & $\begin{array}{l}\text { Significativa e direta apenas com o } \\
\text { Componente conativo das atitudes } \\
\text { retaliatórias }\end{array}$ \\
\hline \multirow{4}{*}{ 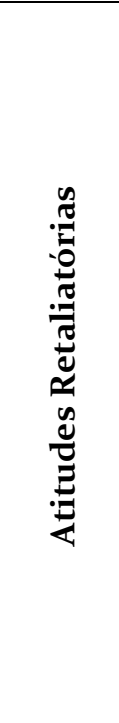 } & Percepção & $\begin{array}{c}\text { Nunca } \\
\text { percebidas }\end{array}$ & $\begin{array}{l}\text { Significativas e diretas } \\
\text { (positivas) com o } \\
\text { Julgamento e com o } \\
\text { Componente conativo }\end{array}$ & \begin{tabular}{|c|} 
Significativa e direta com a maioria das \\
variáveis de valores organizacionais (exceção: \\
Domínio e Tradição) e apenas Estabilidade \\
dos valores do trabalho
\end{tabular} \\
\hline & Julgamento & $\begin{array}{l}\text { Muito } \\
\text { injustas }\end{array}$ & $\begin{array}{c}\text { Significativas e diretas } \\
\text { (positivas) com todas as } \\
\text { demais variáveis de atitudes } \\
\text { retaliatórias }\end{array}$ & \begin{tabular}{|c|} 
Significativa e direta com a maioria das \\
variáveis de valores organizacionais (exceção: \\
Domínio) e \\
Realização e Relações sociais dos valores do \\
trabalho
\end{tabular} \\
\hline & $\begin{array}{c}\text { Componente } \\
\text { afetivo }\end{array}$ & Indignação & $\begin{array}{l}\text { Significativas e diretas } \\
\text { (positivas) com o } \\
\text { Julgamento e com o } \\
\text { Componente conativo } \\
\end{array}$ & $\begin{array}{l}\text { Significativa e direta com s Autonomia e } \\
\text { Bem-Estar dos valores organizacionais } \\
\text { e Estabilidade dos valores do trabalho }\end{array}$ \\
\hline & $\begin{array}{c}\text { Componente } \\
\text { conativo }\end{array}$ & $\begin{array}{c}\text { Propensão a } \\
\text { não retaliar }\end{array}$ & \begin{tabular}{|c|} 
Significativas e diretas \\
(positivas) com todas as \\
demais variáveis de atitudes \\
retaliatórias
\end{tabular} & \begin{tabular}{|c|} 
Significativa e direta com a maioria das \\
variáveis de valores organizacionais (exceção: \\
Bem-Estar, Domínio e Tradição) e Relaçôes \\
sociais e Prestígio dos valores do trabalho
\end{tabular} \\
\hline
\end{tabular}

Quadro 1. Síntese dos resultados

Nota. Fonte: Dados da pesquisa. 
A partir dessa síntese, algumas implicações podem ser traçadas. Para a teoria, entendese que valores organizacionais e do trabalho estão significativamente entrelaçados, fortalecendo percepções de outros estudos sobre as temáticas e aprofundando no que tange ao grupo especificamente aqui investigado, ou seja, jovens trabalhadores. Para esses sujeitos, especificamente, o valor organizacional "autonomia" parece ser o mais decisivo no que tange as suas potencialidades de adotar comportamentos deletérios, isto é, suas atitudes retaliatórias. Por outro lado, a heterogeneidade dos resultados dos testes de correlação indica que retaliação e valores podem não ser construtos congruentes, o que também abre espaço para pesquisas futuras.

Desse modo, pode-se alinhar, no que tange a implicações para as práticas para a gestão, que "realização", tanto no nível organizacional quanto no do trabalho pelo qual o jovem está diretamente responsável, é um valor a ser observado no cotidiano laboral desses trabalhadores, sendo recomendáveis políticas e práticas diretamente voltadas para sua comunhão no interior da empresa, o que pode se dar por meio de avaliações pessoais mais freqüentes, que englobem desempenho, resultado e potencial, além de mais amplas e participativas. Isso pode contribuir para a elevação do prestígio, fundamental para os níveis de satisfação com o trabalho e, também, para o desenvolvimento do jovem em várias esferas, promovendo sua consolidação no âmbito profissional. Por outro lado, alinhar esse valor a valores formalmente definidos e difundidos na organização pode promover uma integração maior entre os jovens aprendizes e os demais empregados. Em relação às questões que envolvem retaliação, perceber que tais jovens dificilmente agem assim é algo desejável para a empresa, de modo geral; no entanto, deve-se permanecer atento para situações potenciais de injustiça pois, mesmo que eles optem por não retaliar, isso não quer dizer que elas não existam. Isso implica em estreitar a comunicação com esses jovens, assim como entre eles próprios e entre eles e os demais trabalhadores, de modo a se estabelecer relações de confiança que não apenas permitam, mas promovam o trânsito de informações visando um ambiente mais saudável e mais produtivo.

\section{Considerações Finais}

O objetivo geral deste estudo foi analisar como se configuram valores organizacionais, 
valores do trabalho e atitudes retaliatórias de jovens trabalhadores de uma empresa pública que atua em todo território nacional.

Quanto aos valores, "realização no trabalho" e "realização na organização" são os mais comungados pelos jovens aprendizes abordados, o que denota certa congruência entre seus objetivos e os da organização. Por outro lado, o orgulho da organização não se reflete na mesma proporção em relação ao trabalho que efetivamente realizam, em face dos achados relativos a "prestígio (no nível) organizacional" e "prestígio no trabalho", o que corrobora resultados de estudos já citados. A posição dos jovens com relação às variáveis tratadas na parte de atitudes retaliatórias foi previsível, tendo em vista sua aderência aos valores compartilhados, em ambos os níveis observados, e sua pouca experiência de trabalho e na vida, de modo geral. No entanto, os resultados dos testes de correlação surpreenderam devido à referida heterogeneidade dos mesmos quando do cruzamento dos temas.

Dentre as limitações da pesquisa, destacam-se dois fatos: (1) trata-se de um estudo de caso, realizado a partir de uma única fonte de dados (questionários), fatos que restringem suas observações aos jovens respondentes na organização abordada, afinal, mesmo que eles sejam de várias partes do país, é importante esclarecer que eles têm acesso a um trabalho em uma empresa de grande porte e a uma renda que contribui sensivelmente para a manutenção de sua família; (2) muitos dados (e-mail) dos jovens aprendizes da organização não estavam atualizados no seu banco de dados, dificultando o envio do link da pesquisa e, com isso, reduzindo a quantidade de respostas.

Esta pesquisa contribui para a consolidação de duas agendas de estudos: a primeira, no campo do comportamento humano em organizações, ao versar sobre valores organizacionais, valores do trabalho e atitudes retaliatórias, os quais têm sido estudados no país, porém não foram encontrados precedentes com a forma integrada realizada neste estudo. A segunda agenda, sobre diversidade e diferenças, focaliza um grupo "especial” de trabalhadores, notadamente os de menor faixa etária, considerados como público com interesses e comportamentos distintos dos trabalhadores mais experientes. Além disso, em virtude da referida integração entre os temas estudados, optou-se por não trabalhar com hipóteses a priori, abrindo caminho para outros estudos que assim sejam delineados.

Por fim, quanto a sugestões para pesquisas futuras, os resultados ensejam aprofundamento em termos das condições de trabalho dos jovens, que certamente variam 
pelo Brasil afora, tendo em vista suas dimensões continentais e, portanto, variações sócioeconômico-culturais; justifica-se também recomendar aprofundamento na relação entre valores e atitudes retaliatórias, tendo em vista a heterogeneidade dos resultados dos testes de correlação aplicados, os quais não permitiram inferir relações diretas (positivas) entre eles, como conceitualmente a literatura pertinente sugere. Sugere-se, também, ampliar os temas trabalhados em investigações futuras, de modo a se construir modelos mais amplos e robustos para compreensão dos fenômenos em foco e de maneira integrada. Certamente existem outras questões que permeiam tais relações e que podem ser desnudadas com a inserção de outros temas e outras perspectivas metodológicas (abordagem qualitativa; triangulação entre métodos) em pesquisas futuras. 


\section{Referências}

Amorim, L. (2010). O Sílvio Santos do fastfood. Recuperado de http://exame.abril.com.br/revista-santos-fast-food-567013?page=1.

Barling, J., Kelloway, E. K., \& Frone, M. R. (2005). Editor's Overviews: special populations. In J. Barling, E. K. Kelloway, \& M. R. Frone (Eds.) Handbook of Work Stress (401-404). Thousand Oaks: Sage.

Campos, B. A. (2008). Estrutura de valores relativos ao trabalho. In M. L. M. Teixeira (Org.). Valores Humanos E Gestão (389-408). São Paulo: Senac.

Constanzi, R. N. (2009). Trabalho decente e juventude no Brasil. Brasília: OIT.

Cooper, D. R. \& Schindler, P. S. (2008). Métodos de Pesquisa em Administração. Porto Alegre: Bookman.

Decreto $n^{\circ}$ 5.598, de 1 dezembro de 2005. Regulamenta a contratação de aprendizes e dá outras providências Recuperado de http://www.planalto.gov.br/ccivil_03/_ato20042006/2005/decreto/d5598.htm.

Ferreira, M. C., Fernandes, H. A., \& Silva, A. P. C. (2009). Valores organizacionais: um balanço da produção nacional do período de 2000 a 2008 nas áreas de administração e psicologia. Revista de Administração Mackenzie, 10(3), 84-100.

Franco, D. S., Nilles, D. S. O. (2016). Atitudes Retaliatórias de Jovens Trabalhadores: Reflexões de uma Análise Qualitativa. Anais do Encontro da ANPAD, Costa do Sauípe, Brasil, 40.

Franco, D. S., Paiva, K. C. M. (2016). Justiça Organizacional e Comportamentos Retaliatórios: Percepções de Jovens Trabalhadores. Anais do 9 Encontro de Estudos Organizacionais da ANPAD, Belo Horizonte.

Irigaray, H. A. R. (2008, setembro). Discriminação por orientação sexual no ambiente de trabalho: uma questão de classe social? Uma análise sob a ótica da pós-modernidade 
crítica e da Queer Theory. Anais do Encontro de Administração Pública e Governança da $A N P A D$, Salvador.

Kelloway, E. K., Barling, J., \& Hurrell, J. (2006). Editor's Introductionto Part II. In E. K. Kelloway, J. Barling, \& J. Hurrell (Eds.). Handbook of Workplace Violence (93-94). Thousand Oaks: Sage.

Lima, M. E. A. (1995). Os equívocos da excelência. Petrópolis: Vozes.

Loughlin, C., \& Lang, C. (2005). Young workers. In J. Barling, E. K. Kelloway, \& M. R. Frone (Eds.). Handbook of Work Stress (405-430). Thousand Oaks: Sage.

Machado, H. V.(2003). A identidade e o contexto organizacional: perspectivas de análise. Revista de Administração Contemporânea, 7(n.spe), 51-73.

Mendes, A. M. \& Tamayo, A. (1999, setembro). Valores e vivências de prazer-sofrimento nas organizações. Anais do Encontro da ANPAD, Foz do Iguaçu.

Mendonça, H., Flauzino, D. O., \& Tamayo, A. (2004a). Percepção e julgamento da retaliação organizacional: construção e validação fatorial de um instrumento. Estudos de Psicologia, 9(3):543-551.

Mendonça, H., Pereira, C., Tamayo, A., \& Paz, M. G. T. (2004b). Validação fatorial de uma escala de percepção de justiça organizacional. Estudos Saúde e Vida, 30(1), 111-130.

Mendonça, H., \& Tamayo, A. (2003). Construção e validação de um instrumento para a Medida de Atitude em Relação à Retaliação Organizacional (MARO). Avaliação Psicológica, 2(2), 147-153.

Oliveira, S. R. (2011). Ponto de Partida: a juventude e o ingresso no mercado de trabalho. In D. L. S. Ferraz, A. P. Oltramari, \& O. Ponchirolli (Org.). Gestão de pessoas e relações de trabalho (89-112). São Paulo: Atlas.

Oliveira, A. F., \& Tamayo, A. (2004). Inventário de perfis de valores organizacionais. Revista de Administração de Empresas (USP), 39(2), 129-140. 
Paiva, K. C. M. (2012). Valores organizacionais e do trabalho: um estudo com jovens trabalhadores. Anais do 26 Encontro da ANPAD, Rio de Janeiro.

Paiva, K. C. M. (2013). Valores organizacionais e do trabalho: um estudo com jovens trabalhadores brasileiros. Tourism \& Management Studies, 9(2), 100-106.

Paiva, K. C. M., Dutra, M. R. S., Barros, V., \& Santos, A. O. (2013, setembro). Estresse ocupacional e burnout de jovens trabalhadores. Anais do Encontro da ANPAD, Rio de Janeiro.

Paiva, K. C. M., \& Leite, N. E. (2011). Justiça no Trabalho e Atitudes Retaliatórias: um estudo com servidores técnico-administrativos de uma instituição federal de ensino superior. Revista Gestão \& Tecnologia, 11(1), 1-11.

Paiva, K. C. M., Macedo, M. B., Irigaray, H. A. R., Dutra, M. R. S., Ferreira, J. M. P., \& Rios, J. E. (2015, setembro). Retaliação em Call Center: Vozes de Diferentes, Relatos de Semelhanças? Anais do Encontro da ANPAD, Rio de Janeiro.

Paiva, K. C. M., \& Souza, C. M. O. (2016). Valores organizacionais em e do trabalho: um estudo com jovens trabalhadores brasileiros. Tourism E Management Studies,12(1), 203210.

Perry, E. L., \& Parlamis, J. D. (2006). Age and ageism in organizations: a review and consideration of national culture. In A. M. Konrad, P. Prasad, \& J. K. Pringle (Eds.). Handbook of Workplace Diversity (345-370). London: Sage.

Pochmann, M. (1998). A inserção ocupacional e o emprego dos jovens. São Paulo: ABT.

Porto, J. B. (2005). Mensuração de Valores no Brasil. In A. Tamayo, \& J. B. Porto (Orgs.). Valores e Comportamento nas Organizações (96-119). Petrópolis: Vozes.

Porto, J. B., \& Tamayo, A. (2003). Escala de Valores Relativos ao Trabalho - EVT. Psicologia: Teoria e Pesquisa, 19(2), 145-152.

Porto, J. B., \& Tamayo, A. (2008). Valores do Trabalho. In M. M. M. Siqueira (Org.). Medidas do Comportamento Organizacional: ferramentas de diagnóstico e de gestão (295-307). 
Porto Alegre: Artmed.

Rios, J. E., Paiva, K. C. M., Rocha, M. S., \& Ferreira, J. M. P. (2015). Qualidade de vida no trabalho: um estudo longitudinal com jovens-trabalhadores. Anais do 3 Congresso Brasileiro de Estudos Organizacionais, Vitória.

Rocha, M. S., \& Paiva, K. C. M. Relações Fronteiriças entre as Dimensões do Comprometimento Organizacional: Contribuições de um Estudo com Jovens Trabalhadores. Anais do 40 Encontro da ANPAD, Costa do Sauípe.

Rokeach, M. J. (1973). The nature of human values. New York: Free Press.

Schwartz, S. H. (2008). Há aspectos universais na estrutura e no conteúdo dos valores humanos? In Teixeira, M. L. M. (Org.). Valores Humanos E Gestão - novas perspectivas (55-85). São Paulo: Senac.

Souza, M. B. C. A., Helal, D. H., \& Paiva, K. C. M. (2016) Burnout e jovens trabalhadores: um estudo qualitativo em Recife / PE. In M. Alcoforado, E. Jesus, S. N. Jesus, P. Pinto, \& . Baptista, (Orgs.). Gestão de Recursos Humanos: Questões atuais (227-242) Faro (Portugal): Universidade do Algarve.

Tamayo, A. (2008). Valores Organizacionais. In M. M. M. Siqueira, (Org.). Medidas do Comportamento Organizacional: ferramentas de diagnóstico e de gestão (309-340). Porto Alegre: Artmed.

Tamayo, A. (2005). Impacto dos valores pessoais e organizacionais sobre o comportamento organizacional. In A. Tamayo, \& J. B. Porto. Valores e Comportamento nas Organizações (160-186). Petrópolis: Vozes.

Tamayo, A., \& Borges, L. O. (2006) Valores do trabalho e das organizacionais. In M. Ros, \& V. V. Gouveia (Orgs.). Psicologia Social dos Valores Humanos (397-431). São Paulo: Senac.

Tamayo, A., \& Porto, J. B. (2005). Parte I - Teoria e medidas de valores. In A. Tamayo, \& J. B. Porto (Orgs.). Valores e Comportamento nas Organizações (17-19). Petrópolis: Vozes. 
Tucker, S., \& Loughlin, C. (2006). Young workers. In E. K. Kelloway, J. Barling, \& J. Hurrell (Eds.). Handbook of Workplace Violence (417-444). Thousand Oaks: Sage.

Vergara, S. C. (2009). Projetos e relatórios de pesquisa em administração. São Paulo: Atlas. 